Aroueología Y SOCIEDAD

№ 30,2015 : 171-183

ISSN: $0254-8062$

RECIBIDO: ABRIL DEL 2015

ACEPTADO: MAYO DEL 2015

\title{
RECUERDOS CLANDESTINOS: DE LAS LUMINOSAS TRINCHERAS DE COMBATE A LOS LUGARES DE LA MEMORIA DE SENDERO LUMINOSO EN DIVERSOS CEMENTERIOS DEL DEPARTAMENTO DE LIMA
}

\author{
FLAVIO ANTONIO Estrada MORENO \\ INSTITUTO DE MEDICINA LEGAL \\ y CIENCIAS ForenSES DEL MINISTERIO PÚBLICO \\ flavio_estrada@hotmail.com
}

\section{RESUMEN}

A partir de 1986 miembros de Sendero Luminoso estructuraron quince lugares de la memoria en diversos cementerios del departamento de Lima. En ellos se libró un constante conflicto de más de dos décadas en el que colores, símbolos y frases fueron usados para mantener esas memorias clandestinas constantemente renovadas.

Palabras claves: lugar de la memoria, violencia interna, pasado reciente, memoria clandestina.

\section{ABSTRACT}

Since 1986 members of Shining Path structured fifteen places of memory in various cemeteries of the department of Lima. A constant conflict over two decades in which colors, symbols and phrases were used to keep those clandestine memories constantly renewed.

KEYWORDS: Place of memory, internal violence, recent past, clandestine memory. 
“...nosotros matamos menos que otros gobiernos..."

Jorge Trelles, vocero del partido Fuerza 2011

(19 de mayo del 2011 en una entrevista difundida en televisión)

\section{INTRODUCCIÓN}

Todos tenemos memoria. Nuestras diarias percepciones son convertidas en recuerdos de largo plazo, ello nos hace ser quienes somos (Foer 2007). Muchas veces nuestros recuerdos nos atrapan en el limbo entre un pasado que no se va y un presente que llega a duras penas. Recordamos mejor aquellos sucesos que nos son desagradables y que lacera nuestro ánimo y revive la sensación tantas veces ella es recordada. Sin embargo no recordamos los hechos tal cual sucedieron sino tal cual lo percibimos con las naturales modificaciones que ello implica.

Recurrimos a nuestra memoria porque ella es necesaria para consolidar la identidad de individuos o de grupos que se reconozcan en él ya que sin este sentimiento de propia identidad ${ }^{1}$ nos sentiríamos constantemente amenazados. El individuo necesita por lo tanto saber quién es y a qué grupo pertenece (Todorov s/f : 8, 9). A lo largo de los siglos nuestra especie ha procurado transmitir sus recuerdos ${ }^{2}$ ya sea a través de la palabra oral primero y escrita luego, o creando entornos que así nos lo recuerden. Preservamos nuestro pasado (y a veces lo hacemos de manera obsesiva) construyendo museos, bibliotecas y monumentos. Y de entre ellos los museos son claros ejemplos de lugares destinados para guardar los recuerdos materiales de culturas extintas que se encuentran cada vez más lejanas en el tiempo. En épocas recientes podemos mencionar el "Ojo que llora" un monumento dedicado a las personas muertas y desaparecidas durante la época de la violencia en el Perú, de la misma manera podemos mencionar el centro para la Memoria Colectiva, actualmente en manos de la Defensoría del Pueblo y el muy publicitado y aun inconcluso Museo o Lugar de la Memoria rebautizado como Lugar de la Memoria, la Tolerancia y la Inclusión Social. Hasta el año 2010 existían en todo el Perú 101 sitios de la memoria (Reátegui 2010).

De las memorias que conservamos se encuentran la de nuestros muertos a quienes hemos destinado lugares para conservarlos y realizar en ellos periódicos rituales que rememoren al familiar y a su vez nos recuerda nuestro propio inevitable destino. Pero los muertos y los lugares en donde ellos son depositados son también usados para fines alejados de toda trama religiosa como veremos más adelante.

La historia, tanto la lejana como la reciente, nos brinda evidencias de la destrucción de esas construcciones materiales con el afán de borrar toda señal de la existencia previa de un gobernante caído en desgracia o la invasión y posterior triunfo de una ideología fundamentalista. La historia de nuestro pasado reciente ${ }^{3}$, como muchos de los países que sufrieron tiempos de violencia interna, nos revela

1.- Nuestra identidad es ese conjunto de características genotípicas, fenotípicas, sociales, culturales y adquiridas que nos incluye, excluye e individualiza.

2.- Un recuerdo es una configuración de conexiones almacenada entre las neuronas del cerebro (Foer 2007).

3.-Silva Santisteban denomina a esto historia de nuestro tiempo el cual se sustenta en el testimonio personal. Esta historia oral tiene su prueba en la experiencia vivida, en la que se sobreponen emoción, sentimientos, ideales y recuerdos en los que aflora espontáneamente la subjetividad del propio narrador (Silva Santisteban 1995). En el registro de los sucesos comprendidos entre 1980 al 2000 el Informe Final de la Comisión de la Verdad y Reconciliación Nacional (CVR) se constituye en un libro de historia de nuestro pasado reciente. 
dos posiciones opuestas: aquellos que trataban de borrar de la memoria el recuerdo de un suceso y aquellos otros que trataron, y tratan, de preservar la memoria de los mismos.

Pero que sucede con la memoria de aquellos otros protagonistas, aquellos que se encuentran en el otro lado de la orilla y cuya ideología se niega a desaparecer?. Un caso investigado a lo largo de 8 años realizado en 15 cementerios ubicados en el departamento de Lima y vinculados a los sucesos de los penales de junio de 1986 nos demostró el valor que tienen los símbolos, colores y frases para crear y recrear un lugar para esa memoria ${ }^{4}$ clandestina.

\section{SOBRE RECUERDOS, MEMORIAS, PASADO RECIENTE Y LUGARES DE LA MEMORIA}

Jelin (2012) señala que cuando compartimos nuestras vivencias propias ellas refuerzan y estrechan los lazos de pertenencia a un grupo o comunidad, de esta manera se constituye nuestro universo social. La memoria individual se convierte entonces en una memoria colectiva y esta a su vez se encuentra incorporada dentro de un contexto social y respondiendo a esas necesidades y valores (Jelin 2012). Las memorias se encuentran en conflicto unas con otras ya que cada una lucha por su verdad. En situaciones como las que vivió nuestro país hablamos de memorias de sufrimiento extremo, que se encuentran al límite, cuyo recuerdo es completamente distinto según se trate de los que ganaron un conflicto o de los que se encuentran en el lado opuesto (Jelin 2012)

\section{RECORDANDO NUESTRO PASADO RECIENTE}

En nuestra memoria queda aún la imagen ${ }^{5}$ de un miembro de la Guardia Civil quien subido en un poste de alumbrado público bajaba el cadáver de un perro que había sido colgado en una calle del Centro de Lima. Ello ocurrió la mañana del 26 de diciembre de 1981 y marcó la cercanía de una guerra que creíamos todavía lejana. Sendero Luminoso le había declarado la guerra al estado peruano el 17 de mayo de $1980^{6}$ dando principio a la etapa denominada Inicio de la Lucha Armada ${ }^{7}$ (ILA) y es a través del sistema educativo que encontró la mejor forma de dispersión (CVR 2002). Años después el

4.- Jelin (2012) plantea tres premisas centrales para analizar el pasado: “1) Entender las memorias como procesos subjetivos, anclados en experiencias y en marcas simbólicas y materiales. 2) Reconocer a las memorias como objeto de disputas, conflictos y luchas, lo cual apunta a prestar atención al rol activo y productor de sentido de los y las participantes en esas luchas, enmarcados en relaciones de poder. 3)Historizar las memorias, o sea, reconocer que existen cambios históricos en el sentido del pasado, así como en el lugar asignado a las memorias en diferentes sociedades, climas culturales, espacios de luchas políticas e ideológicas" (Jelin 2012:36). Con respecto a lugares de la memoria esta misma autora señala que "...monumentos, memoriales, placas recordatorias y otras marcas, son las maneras que en que actores oficiales y no oficiales tratan de dar materialidad a las memorias. Hay también fuerzas sociales que tratan de borrar y de transformar, como si al cambiar la forma y la función de un lugar, se borrará la memoria." (Jelin 2012: 85).

5.- Una fotografía de este suceso se puede apreciar en la página 13 de Caretas (2003).

6.- El arquitecto Fernando Belaunde Terry gobernaba por segunda vez el Perú. Informado sobre tales hechos este los atribuyó a la acción de abigeos (Portocarrero 2000).

7.- Los planes militares que Sendero Luminoso tenia eran: $1^{\circ}$ Plan: Inicio de la lucha armada (17 de mayo a diciembre de 1980), $2^{\circ}$ Plan: desplegar la guerra de guerrillas (de enero de 1981 a enero de 1983), $3^{\circ}$ Plan: Conquistar la base de apoyo (de mayo de 1983 a setiembre de 1986), 4 Plan: Desarrollar bases de apoyo (de noviembre de 1986 a julio de 1989), $5^{\circ}$ Plan: desarrollar bases en función de la conquista del poder (de agosto de 1989 a agosto de 1992), $6^{\circ}$ Plan: Construir la conquista del poder (de setiembre de 1992 a noviembre de 1999) (CVR 2002). 
conflicto armado interno produjo un número aproximado ${ }^{8}$ de entre 15,000 y 16, 000 peruanos y peruanas fallecidos y desaparecidos durante los años 1980 al 2000. Los actores en este conflicto fueron el Partido Comunista del Perú Sendero Luminoso (PCP SL), el Movimiento Revolucionario Tupac Amaru (MRTA), las Fuerzas Policiales (FFPP), las Fuerzas Armadas (FFAA), los grupos paramilitares Rodrigo Franco y Grupo Colina y los ronderos.

La CVR también señala que la prédica senderista tuvo aceptación en función a la incapacidad de un estado y de las elites del país para responder a las demandas de una juventud que a lo largo de los años se frustraba en su constante esfuerzo de movilidad social y de aspiración al progreso (CVR 2002). Sendero Luminoso reclutaba a nuevos miembros entre los que se encontraban tanto en la escuela y en la educación superior pública aprovechando las deficiencias de una escuela que enseñaba patrones autoritarios ${ }^{9}$ a la vez que rígidos y de mala calidad (CVR 2002).

Finalmente el 12 de setiembre de 1992 el Grupo Especial de Inteligencia (GEIN) de la Dirección Contra el Terrorismo (DINCOTE) logra la captura de Manuel Rubén Abimael Guzmán Reinoso (a) "Presidente Gonzalo" o "Camarada Gonzalo".

\section{LOS SUCESOS QUE DIERON ORIGEN A LA FORMACIÓN DE SITIOS CON RESTOS HUMANOS Y ELEMENTOS ASOCIADOS}

En $1986^{10}$ Sendero Luminoso (SL) tenía un amplio control sobre diversos centros penitenciarios ${ }^{11}$. Para ese año estos lugares ya habían dejado de ser las "mazmorras de la reacción" para convertirse en las "luminosas trincheras de combate". En junio de 1986 se produjo un coordinado amotinamiento en los penales de San Juan Bautista ("El Frontón"), San Pedro ("Lurigancho") y Santa Bárbara. De acuerdo a Uceda (2004) en el Penal de Lurigancho los amotinados que ya se habían rendidos fueron obligados a salir por un boquete, que había servido para que miembros de la Guardia Republicana (GR) ingresaran al Pabellón Británico. Afuera los esperaba un comando de aniquilamiento. Producto de los enfrentamientos contra las fuerzas armadas y policiales se registra la muerte de varios cientos de internos de los denominados Pabellón Azul (El Frontón) y Pabellón Industrial (Lurigancho). Mediante un decreto supremo aprobado por el Consejo de Ministros de aquel entonces se declaraba a los tres penales como "zona militar restringida"12 bajo competencia y jurisdicción del Comando Conjunto de las Fuerzas

8.- De acuerdo a Escobar (2012) diversas instituciones manejan distintas cifras. El Equipo Peruano de Antropología Forense (EPAF) estima que fueron 15, 173 personas, El Instituto de Medicina Legal (IML) ubica a los desaparecidos entre 15, 000 y 16,000. Por su parte, la Coordinadora Nacional de Derechos Humanos (CNDDHH) conjuntamente con el Centro Andino de Investigaciones Antropológico Forenses (CENIA) manejan la cantidad de 12,859.

9.- De la misma opinión es Ansion (s/f) quien enfatiza que fueron dos los factores para que Sendero Luminoso encontrara en la escuela un terreno propicio: el autoritarismo y el dogmatismo del profesorado lo que en la práctica significaba que ellos imponían todo sin una explicación racional acostumbrándolos desde pequeños a repetir todo sin pensarlo.

10.- Alan García Pérez fue presidente del Perú en dos oportunidades: de 1985 a 1990 y de 2006 al 2011. Los hechos narrados ocurrieron durante el desarrollo del XVII Congreso de la Internacional Socialista que se desarrollaba en Lima durante su primer gobierno.

11.- Un estudio realizado por Pérez Guadalupe en 1994 y que es mencionado por Rénique (2003) señala que el Penal de Lurigancho es un lugar en donde las normas de convivencia están determinados por los propios presos.

12.- De esta manera se impedía la presencia de fiscales y jueces civiles que pudiesen esclarecer en forma independiente lo sucedido (CVR 2002). 
Armadas señalando su vigencia a partir del mismo día de su promulgación. Ello en la práctica significaba que el levantamiento de los cadáveres, análisis, identificación y su posterior inhumación se encargaba a la justicia militar (CVR 2002). El registro de los cementerios en donde habían quedado depositados los cadáveres debía ser comunicado al Instituto Nacional Penitenciario (INPE) para que este a su vez informe a los familiares (Haya 1987). Según Haya (1987: 113) y Ames (1988: 353) los cadáveres fueron depositados las noches del 20 al 21 de Junio de 1986 en los cementerios de Imperial, San Vicente de Cañete, Pachacamac, Chosica, Chaclacayo, Vitarte, Barranco, Surquillo, Callao, Lima, Puente Piedra, Huaral, Chancay, Huacho y Barranca. A partir de estos sucesos Sendero Luminoso declara el 19 de junio como "Día de la Heroicidad".

\section{De SITIOS CON RESTOS hUMANOS A LUGARES DE MEMORIAS CLANDESTINAS}

En el presente caso analizado los restos humanos y elementos asociados se encuentran en 15 cementerios de Lima y provincias. En ellos fueron depositados más de un centenar de cadáveres producto de los sucesos antes mencionados y específicamente del Penal de San Pedro (Lurigancho). Los cementerios fueron explorados los años 2005, 2010 y 2013 tiempo durante el cual pudimos registrar frases, símbolos y colores que cubrían las lapidas y cuyas pinturas fueron renovadas, cubiertas y nuevamente renovadas durante ese lapso. La totalidad de los restos humanos se encuentran depositados dentro de nichos en sus respectivos pabellones. Es en estos lugares que miembros de Sendero Luminoso practicaron actividades que trataron de mantener la memoria ${ }^{13}$ de los sucesos del 18 y 19 de junio del 1986.

\section{CONSTRUYENDO LUGARES PARA LAS MEMORIAS CLANDESTINAS}

Nora (1984: 33) señala que:

“...los lugares de la memoria ${ }^{14}$ pertenecen a dos reinos, es los que les confiere interés, pero también complejidad: simples y ambiguos, naturales y artificiales, abiertos inmediatamente a la experiencia más sensible, y al mismo tiempo, fruto de la elaboración más abstracta. Son lugares, efectivamente, en los tres sentidos de la palabra: material simbólico y funcional, pero simultáneamente en grados diversos...si bien es cierto que la razón fundamental de un lugar de la memoria es detener el tiempo, bloquear el trabajo del olvido, fijar un estado de cosas, inmortalizar la muerte, materializar lo inmaterial para encerrar el máximo de sentidos en el mínimo de signos....los lugares de la memoria no viven sino por su aptitud para la metamorfosis, en el incesante resurgimiento de sus significaciones y la arborescencia imprevisible de sus ramificaciones..."

Jelin señala que las memorias se vuelven entonces espacios de lucha política y de ellas las memorias alternativas son clandestinas conservadas y transmitidas por lo tanto en un ámbito más restringido, más íntimo, más familiar o de sociabilidad clandestina debido a que estas memorias son memorias prohibidas (Jelin 2012). Estas marcas en el espacio (los lugares de la memoria) sufren entonces la

13.- Uno de los lugares de la memoria de Sendero Luminoso más antiguo que hemos podido ver se encuentra en el Cementerio General de la ciudad de Huamanga en Ayacucho, allí fueron enterrados los restos de Edith Lagos quien murió en el paraje de Umaca, ubicado entre Andahuaylas y Talavera en el departamento de Apurímac, el 03 setiembre de 1982 como producto de un enfrentamiento con la Guardia Republica de ese entonces .Tenia 19 años al momento de su muerte. Fue su padre, con permiso de las autoridades, quien trasladó el cadáver desde Andahuaylas para ser enterrado en el Cementerio General de Huamanga (Gorriti 2008). Mitificada en vida después de muerta el mito no cesó.

14.- Vidal-Naquet (1996: 19) menciona que un lugar de la memoria es un "espacio que simboliza un tiempo, una transposición espacial cuy a función es evocar precisamente algo que sucedió en el tiempo". 
generación de fuerzas sociales que las tratan de borrar y de transformar como si ello también borrara a su vez la memoria individual o colectiva que se tiene sobre un hecho (Jelin 2003).

Estas definiciones proporcionadas tanto por Nora (1984) y Jelin (2002) nos permiten entonces explicar los hallazgos realizados en los cementerios visitados en donde pudimos registrar un conjunto de elementos constituido por: colores, frases y símbolos que serán descritos a continuación.

\section{COLORES}

Color rojo: Este es uno de los colores mas antiguos que ha sido observado en la casi totalidad de las lapidas. Este color es usado como símbolo de la sangre derramada en distintos enfrentamientos. Con pintura de este color se escribían lemas a la lucha armada en los lugares en donde SL hacia acto de presencia. La hemos podido ver en las paredes de las casas en poblados de la margen izquierda del Río Huallaga y en algunas universidades nacionales de ese entonces.

Color plomo: Es el segundo en antigüedad. Cubre el color rojo en varias lapidas y al parecer esta fue aplicada por miembros de las fuerzas armadas.

Color blanco: Es el más recurrente luego del rojo y el más reciente con respecto a los otros dos. Con este color han sido cubiertos tanto el rojo como el plomo. Sobre este color se diseñaron los iconos católicos relacionados a la muerte.

\section{Frases}

Frase 01: "Al mejor hijo del pueblo asesinado por el gobierno 18 de junio 1986"

Esta frase, realizada con una plantilla, fue escrita a mediados del año 2009 en uno de los cementerios de provincia. Quienes posteriormente trataron de borrarla echaron sobre ella pintura negra, sin lograrlo. Hemos visto un párrafo en un folleto de Sendero Luminoso, referido precisamente a este caso, menciona que algunos de los fallecidos eran "hijos del pueblo" (Comité Central PCP SL 1986). Hijos del pueblo es también el título de una conocida canción vinculada con el movimiento obrero.

Frase 02: "Honor y gloria"

Esta es una frase que Abimael Guzmán usó en los funerales de Augusta La Torre (Guzmán 2009) y al parecer es usada en las exequias de miembros destacados de esta organización.

\section{Símbolos}

Símbolo 01: Hoz y martillo pintado en color amarillo sobre fondo rojo

Este es un símbolo constituido por una hoz que representa a los campesinos y un martillo de cota que representa a los obreros. En general representa a la clase trabajadora y fue usado como símbolo de distintos partidos comunistas incluyendo a Sendero Luminoso. Su visión está asociada al accionar de esta organización en distintas partes del país. En aquellos años durante los recurrentes apagones podíamos ver en los cerros cercanos a la capital este símbolo diseñado con antorchas hechas con latas de leche, retazos de telas y gasolina. En la UNMSM, hasta 1992, era usual ver este símbolo en las diversas facultades del campus universitario. Hace algunos años en un reporte periodístico propalado en un canal de televisión pudimos observar que los remanentes de SL, ya uniformados, usaban un polo negro con la hoz y el martillo impresos. Nada tendría de extraño sino fuese porque el martillo representado era el de carpintero y no el clásico martillo de cota. 


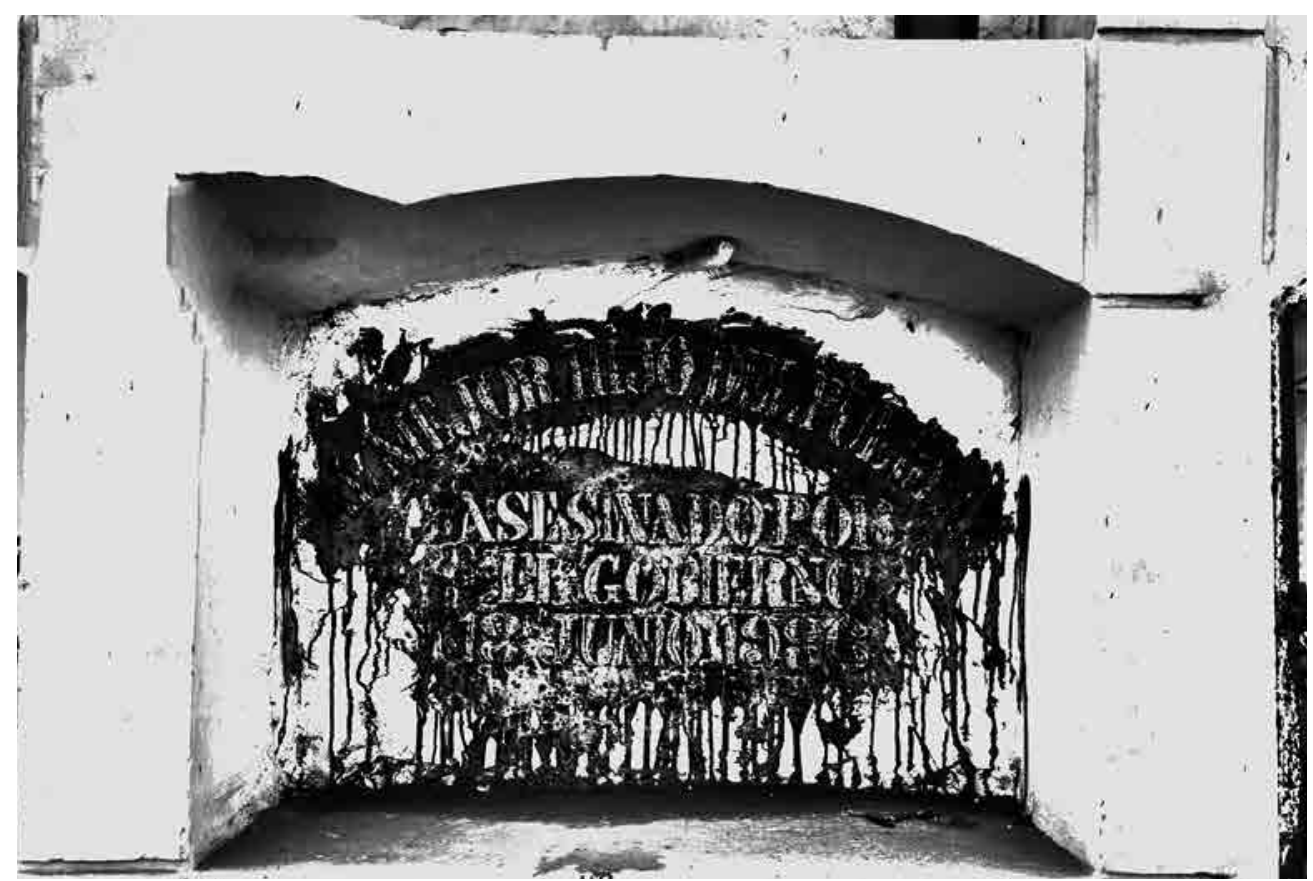

Figura 01: Frase: AL MEJOR HIJO DEL PUEBLO ASESINADO POR EL GOBIERNO 18 junio 1986.

Las letras fueron diseñadas con una plantilla que usó líneas guías. Estas palabras fueron pintadas con color rojo. Sobre ellas fue luego echada pintura de color negro para cubrirla.

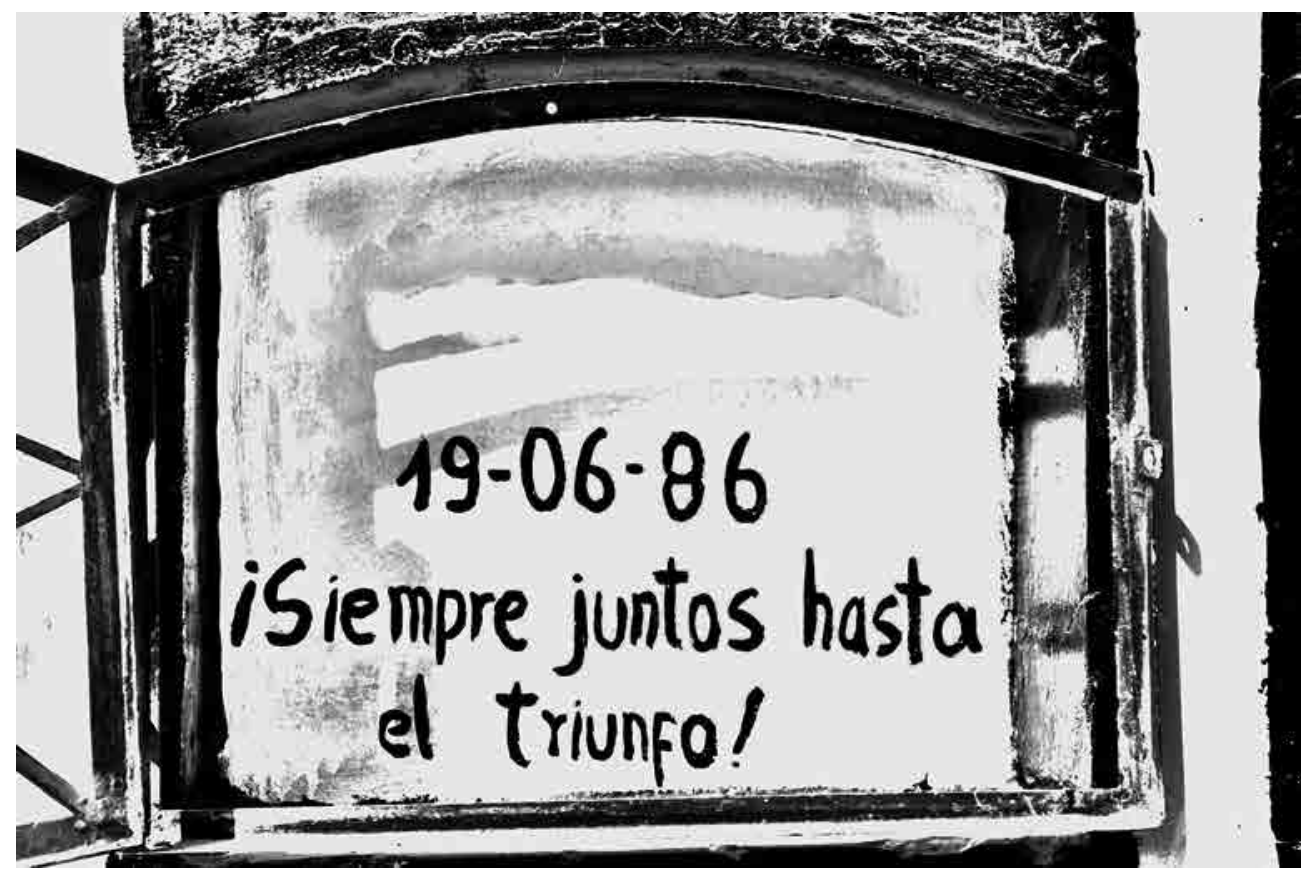

Figura 02: Frase: ¡SIEMPRE JUNTOS HASTA EL FINAL ${ }_{j}$. Letras de color rojo escritas a mano alzada sobre fondo blanco. 


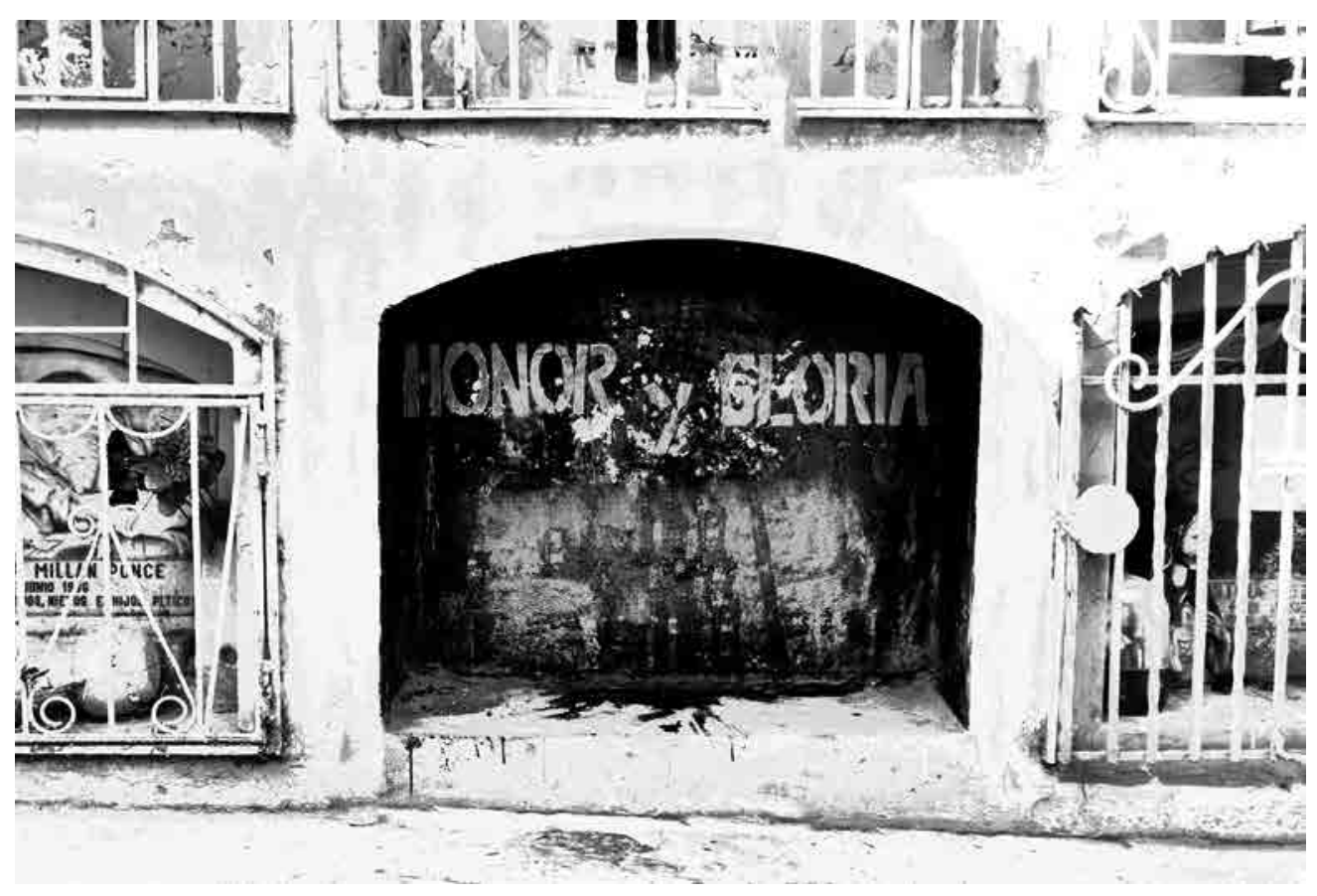

Figura 03: Frase: HONOR Y GLORIA. Letras de color amarillo sobre fondo rojo.

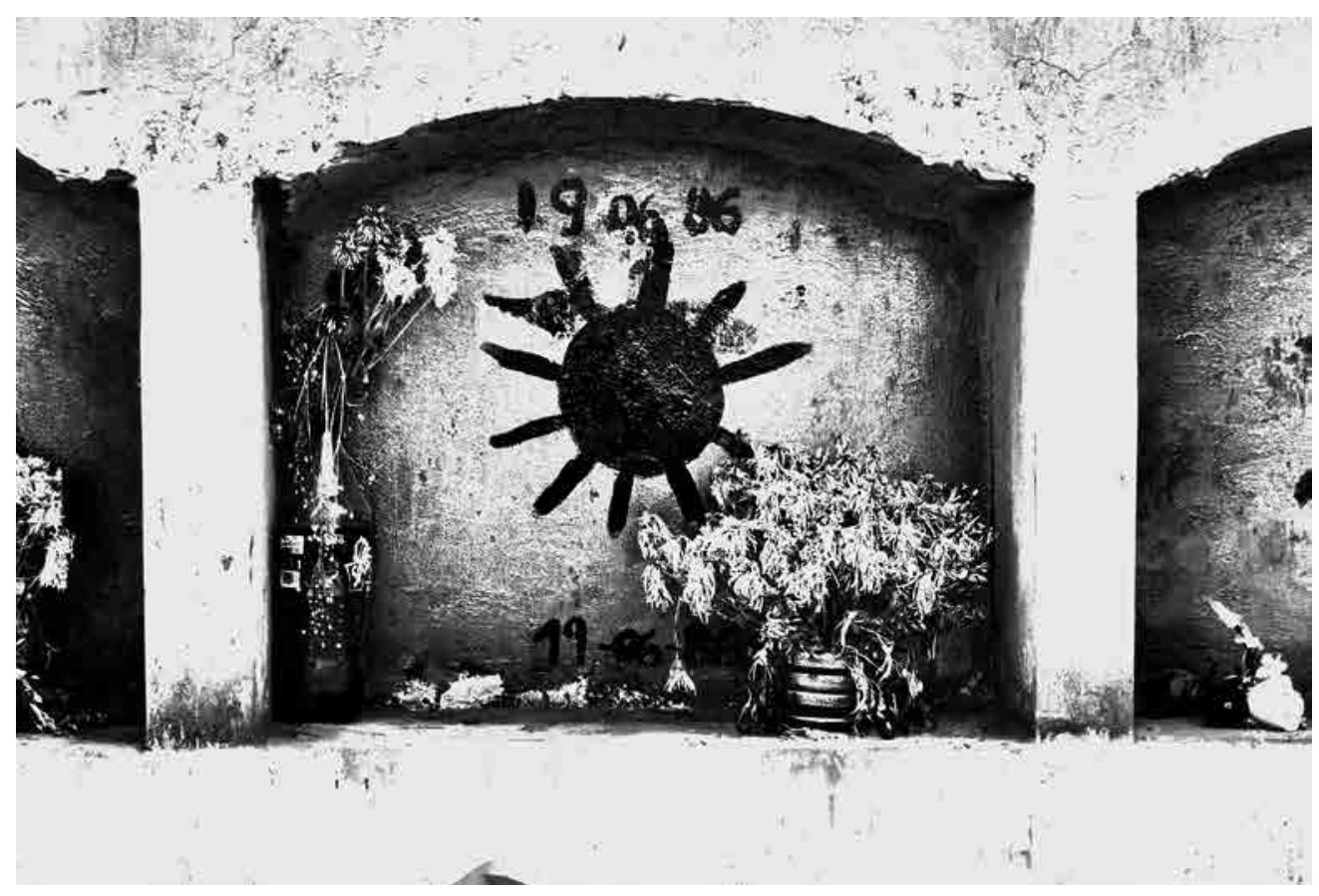

Figura 04: Imagen: Sol rojo sobre fondo amarillo que cubre la imagen de una paloma negra. 


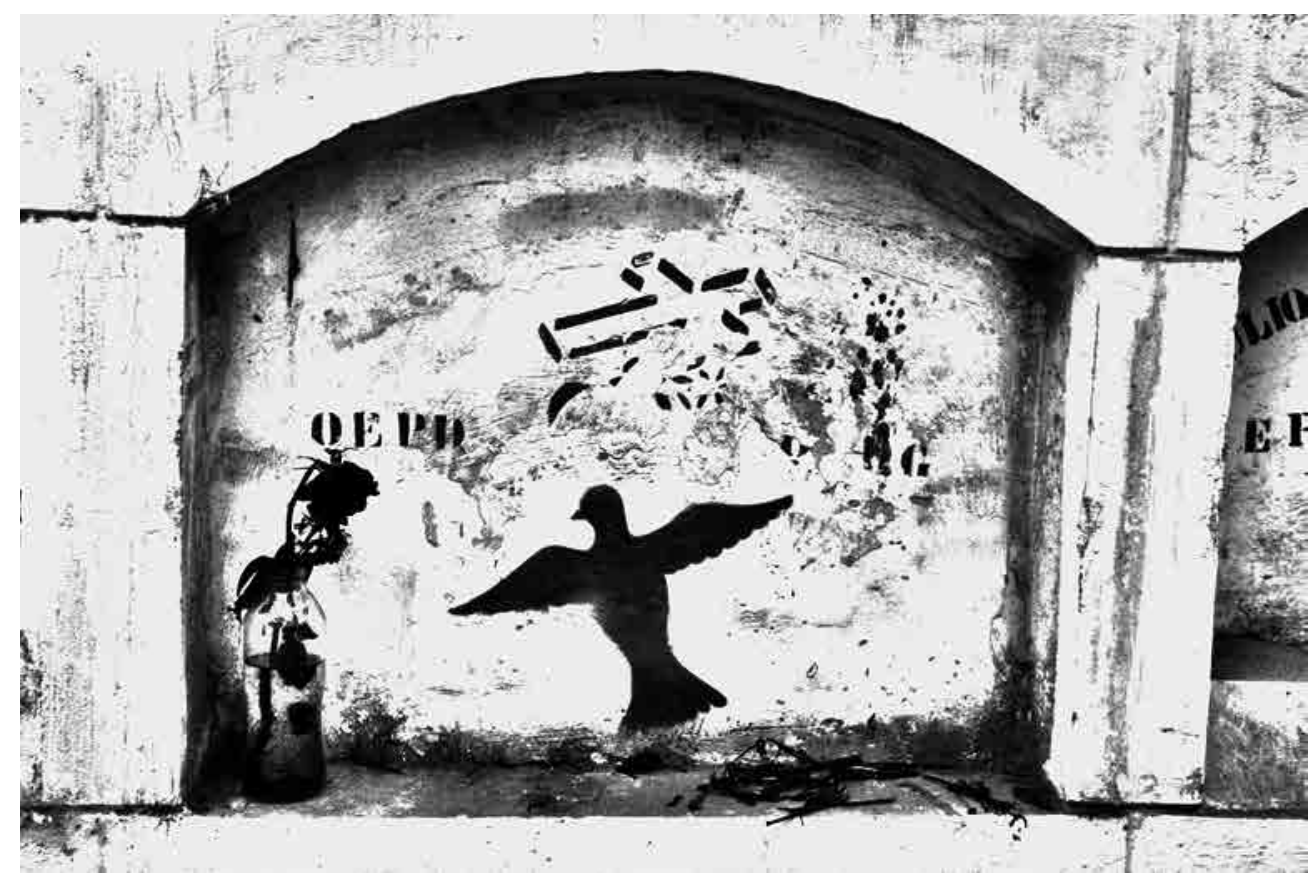

Figura 05: Imagen: Paloma negra hecha con una plantilla coexistiendo con los símbolos católicos.

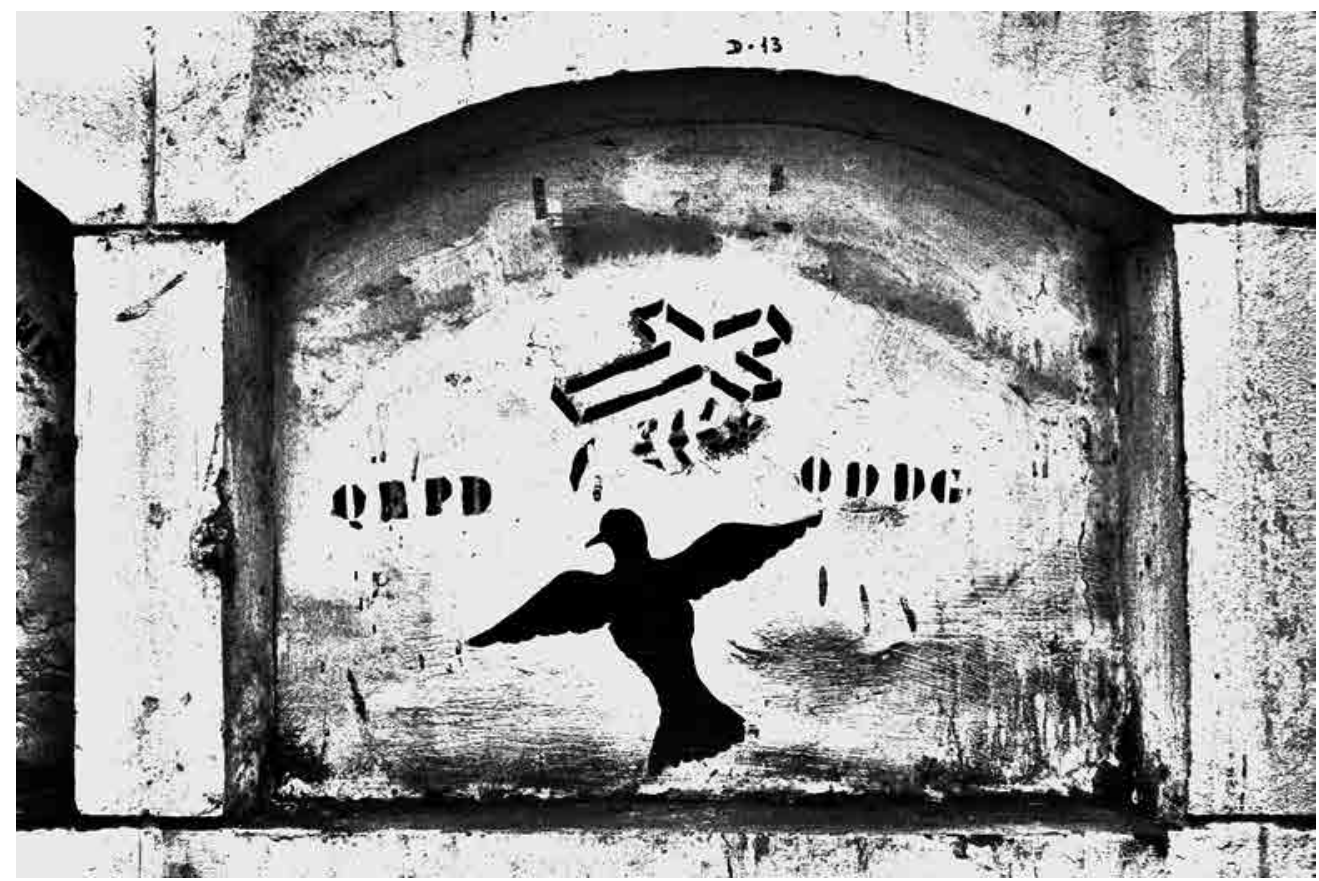

Figura 06: Imagen: Paloma negra hecha con una plantilla coexistiendo con los símbolos católicos. 


\section{Símbolo 02: Paloma negra}

Este ha sido un símbolo recurrente en varias de las lápidas de los cementerios y nada común en la iconografía senderista. De acuerdo a información recopilada en uno de los cementerios esta imagen, pintada al año de los sucesos, tenía inicialmente el color verde, posteriormente fue pintado en color negro. Esta imagen fue hecha usando una plantilla. Hemos podido observar que aun cuando a la lápida se le renovaba el color rojo, o aun el posterior color blanco para cubrir el rojo, se trató en todo momento de que ambas pinturas no tapen este ícono. En algunos cementerios esta imagen coexiste con los símbolos cristianos, como la cruz, llevados quizás por la idea de que se trataba del icono católico que tiene que ver con la resurrección. En nuestra política nacional recordamos este símbolo, si bien no del mismo color, en las elecciones de 1985. De acuerdo a Arévalo (2010) en la campaña de 1985 el entonces partido aprista usó una paloma blanca como símbolo. Por su parte Samborn (1998 : 110) señala que "una blanca paloma de la paz fue añadida al símbolo histórico del partido, la estrella de cinco puntas". Al parecer quienes trataron de ocultar los símbolos no vieron en esta figura alusión a Sendero Luminoso puesto que con el transcurrir del tiempo es la figura que tiene mayor continuidad. Ello nos permite plantear que esta imagen fue usada por miembros de Sendero Luminoso como un medio para recordar tanto al gobernante como al gobierno en que ocurrieron los hechos ya mencionados.

Símbolo 03: Sol rojo sobre fondo amarillo

Este símbolo debió ser hecho entre el año 2010 y 2013 e interesantemente cubre la totalidad de lápidas que tienen la paloma negra en uno de los cementerios de Lima. Menzell (1996, Pag.124) señala que Guzmán era conocido entre sus seguidores como Dr. Puka Inti (Dr. Sol Rojo). Desconocemos si este alias fue usado en zonas urbanas.

\section{Comentarios Y Discusión}

Es notable la sucesión de capas de pintura que trataron a lo largo de los años de cubrir el inicial color rojo realizado por miembros de Sendero Luminoso. Las pinturas que usaron para esta labor fue primero el plomo, posiblemente hecho por miembros de la Fuerzas Armadas y luego el blanco realizado posiblemente por personal de los cementerios. En uno de sitios hemos podido observar que ficticios nombres y fechas fueron realizados sobre una rala pintura blanca que dejaba al descubierto el color rojo y el símbolo de la hoz y martillo. El poco cuidado en el diseño de las letras hechas a mano alzada nos lleva a pensar en la rapidez y quizás la improvisación en su elaboración con fines de ocultar las anteriores inscripciones las cuales ocurrieron entre la visita de enero del 2005 y enero del 2010. La intencionalidad de tratar de ocultar tanto los nombres y apellidos de la persona que se encontraría depositada al interior del nicho así como el color rojo y algunos símbolos es evidente.

Situación totalmente distinta ocurre cuando miembros de SL deciden renovar sus colores o colocar nuevas frases. No se observa rapidez en sus trabajos, si bien para colocar alguna frase usan plantillas, lo que permite una escritura uniforme y rápida, hemos visto que se tomaron el tiempo necesario para trazar líneas guías con el fin de que el diseño se encuentre horizontal. En uno de los cementerios a una cuidadosa pintura de color amarillo se superpone un sol rojo cuyo centro fue diseñado con una plantilla circular. Es evidente que en aquellos cementerios en donde hay una renovación cuidadosa de colores, Sendero Luminoso tiene aún cierta presencia y quizás por eso es que no hay registro de denuncia alguna ante la policía o medios periodísticos. No ocurrió lo mismo con aquellos cementerios que se encuentran en cascos urbanos en donde la última pintura blanca se conservó hasta la última visita realizada en 2013 y son, a la luz de las evidencias, lugares en donde esta organización tiene escasa presencia. 


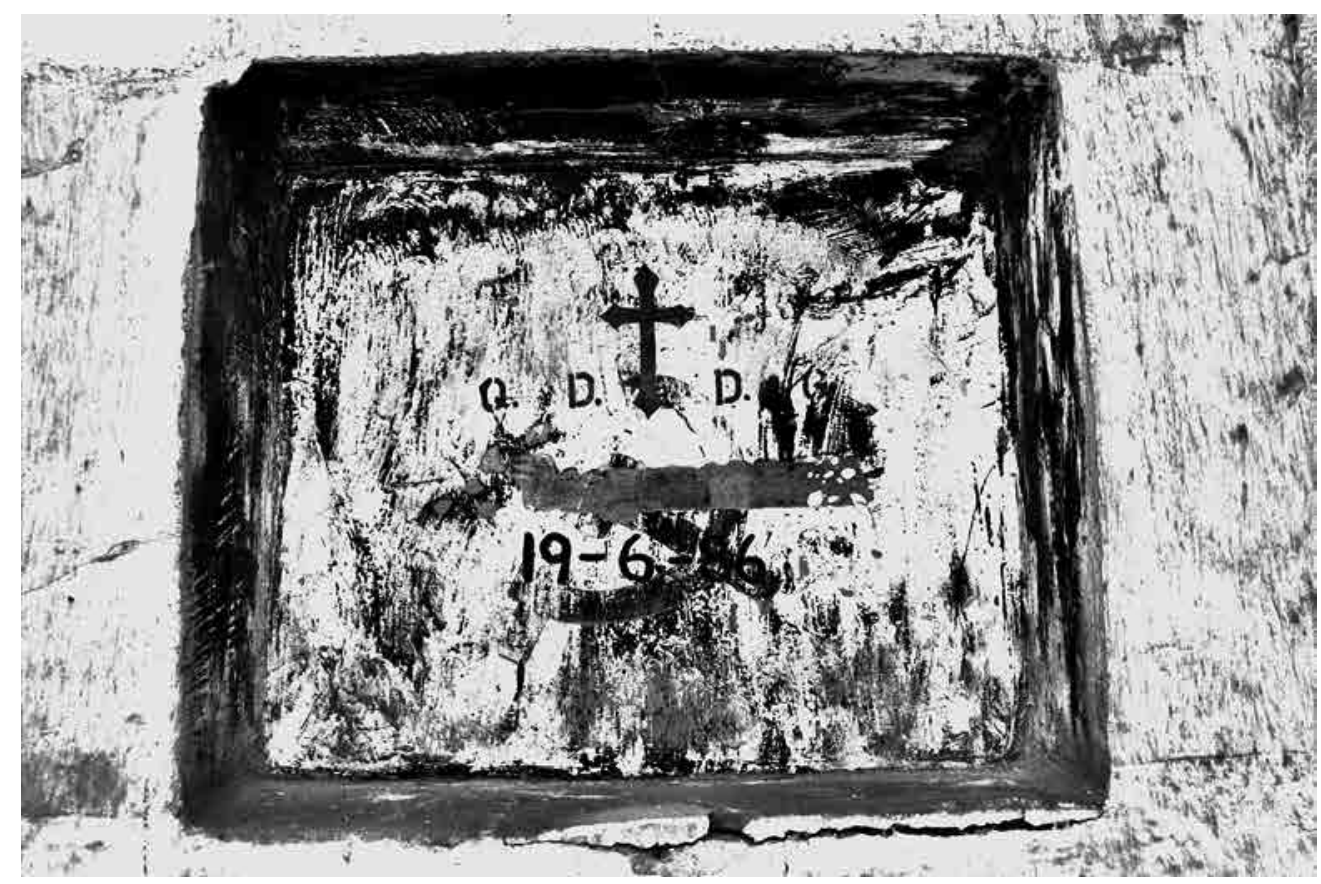

Figura 07: Imagen: Pintura blanca cubriendo el color rojo y el símbolo de la oz y el martillo de cota.

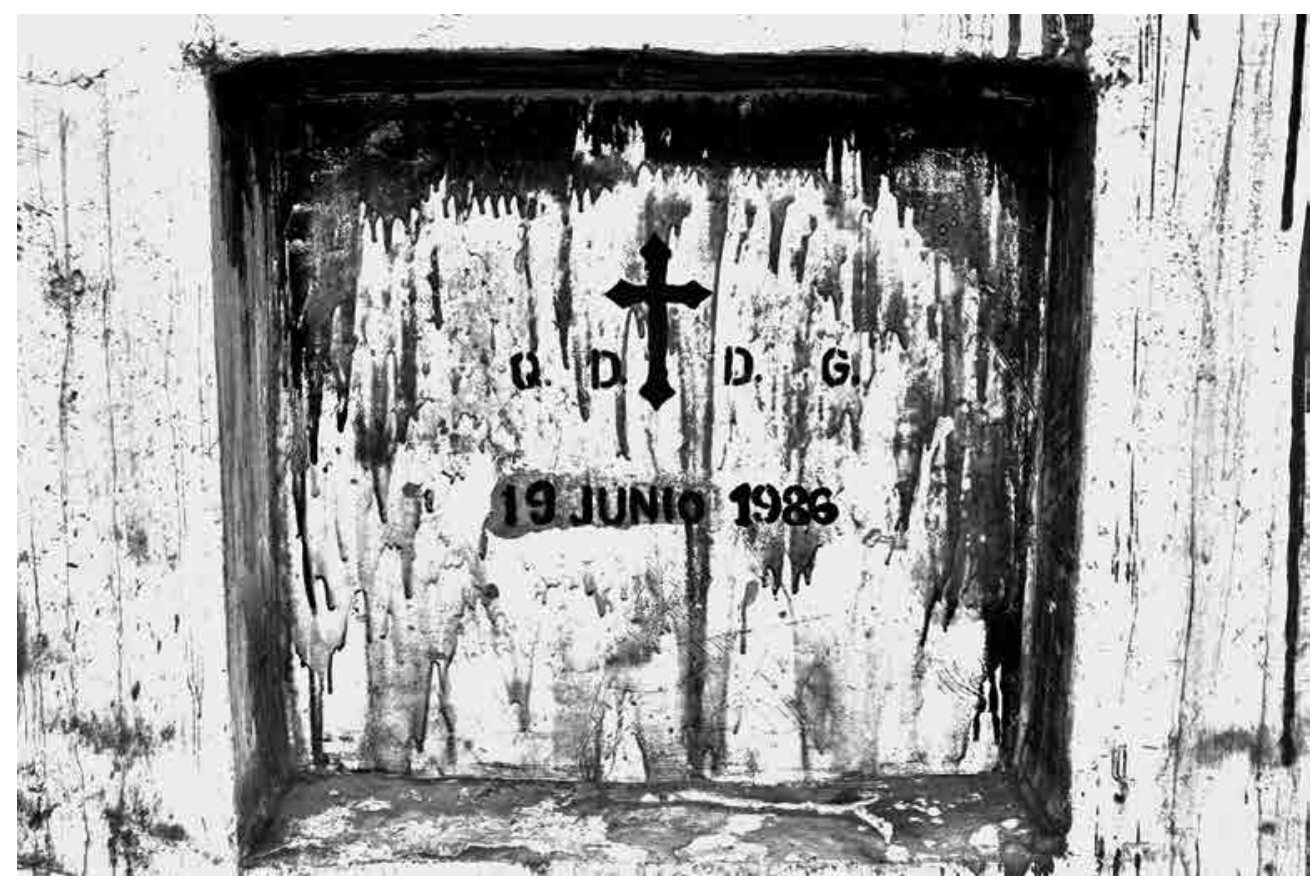

Figura 08: Imagen: Color rojo cubriendo color blanco. 


\section{CONCLUSIONES}

Un silencioso y largo conflicto que duró 27 años se produjo en 15 cementerios del departamento de Lima. Unos tratando de prolongar el recuerdo de los sucesos de los penales de 1986 y los otros tratando de enviar al olvido aquel mismo hecho. En esta batalla los símbolos, frases y colores fueron importantes para crear y recrear lugares de la memoria para Sendero Luminoso en cada uno de estos cementerios.

\section{BibLIOGRAFÍA}

AMES, Rolando (Editor)

1988 Informe al Congreso sobre los sucesos de los penales. Presentado por: Senador Rolando Ames, Senador Jorge del Prado, Diputado Javier Bedoya, Diputado Oscar Felipe V., Diputado Agustín Haya de la Torre, Diputado Áureo Zegarra. Lima, Perú.

ANSION, J.

(s/f) Sendero Luminoso y lo educativo. Biblioteca virtual de Ciencias Sociales. www.cholonautas. edu.pe

ARÉVALO, Juan Aurelio

2010 Conozca la historia detrás de los símbolos de algunos partidos políticos. El Comercio. Domingo 14 de noviembre. Lima, Perú.

Caretas

2003 La verdad sobre el espanto. El Perú en los tiempos del terror. Dossier fotográfico de Caretas. Lima, Perú.

Comité Central del PCP SL

1986 Desarrollar la guerra popular sirviendo a la revolución mundial. Ediciones Bandera Roja. Perú.

ESCOBAR, Ramiro

2012 El silencio de los inocentes. La Republica. Domingo 02 de setiembre. Lima, Perú.

FOER, Joshua

2007 No lo olvide en los archivos del cerebro, nuestra vida perdura o desaparece. National Geographic, Vol. 21-Num. 5.

GUZMÁN, Abimael

2009 De puño y letra. Editorial Mano Alzada. Lima, Perú.

GORRITI, Gustavo

2008 Sendero. Historia de la guerra milenaria en el Perú. Editorial Planeta. Lima, Perú.

HAYA DE LA TORRE, Agustín

1987 El retorno de la barbarie. La matanza de los penales de Lima en 1986. Bahía Ediciones. Lima, Perú.

JELIN, Elizabeth

2003 Memorias y luchas políticas. Jamás tan cerca arremetió lo lejos. Memoria y violencia política en el Perú. Carlos Iván Degregori (editor). Instituto de Estudios Peruanos, Social Science Research Council. Lima, Perú. 
2012 Los trabajos de la memoria. Instituto de Estudios Peruanos. Lima, Perú.

MENZELL, Sewall

1996 Fire in the andes: U.S. foreign policy and cocaine politics in Bolivia and Perú. University Press of America.USA.

NORA, Pierre

1984 Entre memoria e Historia: La problemática de los lugares. Nora, Pierre (dir.): Les Lieux de Mémoire; La Republique París, Gallimard, Pág. XVII-XLIL. Traducción para uso exclusivo de la Cátedra Seminario de Historia Argentina Prof. Fernando Jumar C.U.R.Z.A.-Universidad Nacional de Comahue.

NORA, Pierre

2008 Pierre Nora en Les Lieux de Mémoire. Ediciones Trilce, Montevideo-Uruguay.

PORTOCARRERO GRADOS, Ricardo

2000 El Perú contemporáneo. Historia del Perú. Lexus. Lima, Perú.

REÁTEGUI, Félix (Cord.)

2010 Los sitios de la memoria: procesos sociales de la conmemoración en el Perú. Instituto de Democracia y Derechos Humanos de la Pontificia Universidad Católica del Perú (IDEHPUCP). Primera edición. Lima, Perú.

RÉNIQUE, José Luis

2003 La voluntad encarcelada. Las "luminosas trincheras de combate" de Sendero Luminoso del Perú. Presentado en la reunión de Latin American Studies Association. Dallas, Texas, Marzo 27-29, 2003.

SANBORN, Cynthia

1988 El APRA en un contexto de cambio, 1960-1988. El APRA de la Ideología a la Praxis. Bonilla, H.y Drake, P. (Editores). Centro Latinoamericano de Historia Económica y Social, Lima; Center for Iberian and Latina American Studies, University of California, San Diego; Editorial y Productora Grafica "Nuevo Mundo" EIRL, Lima. Lima, Perú.

SILVA SANTISTEBAN, Fernando

1995 Historia de nuestro tiempo. Universidad de Lima. Fondo de desarrollo editorial. Lima, Perú.

TODOROV, Tzvetan

s/f Los dilemas de la memoria. Traducción del francés de Dulce Ma. Zúñiga. Cátedra Latinoamericana Julio Cortázar. Conferencia Magistral.

UCEDA, Ricardo

2004 Muerte en el pentagonito. Los cementerios secretos del ejército peruano. Editorial Planeta Colombiana. Bogotá, Colombia.

VIDAL-NAQUET, Pierre

1996 Los judíos, la memoria y el presente. Fondo de Cultura Económica. Buenos Aires, Argentina. 